\title{
Determinants to antiretroviral treatment non-adherence among adult HIV/AIDS patients in northern Ethiopia
}

\author{
Berhe Beyene Gebrezgabher ${ }^{1}$, Yigzaw Kebede ${ }^{2}$, Melaku Kindie², Desalegn Tetemke ${ }^{1}$, Mebrahtu Abay ${ }^{1}$ \\ and Yalemzewod Assefa Gelaw ${ }^{2 *}$
}

\begin{abstract}
Background: Adhering 95\% and above of antiretroviral therapy reduces the rate of disease progression and death among people's living human immunodeficiency virus. Though manifold factors have reported as determinant factors of antiretroviral therapy adherence status, perhaps determinants of non-adherence differ up on the activities of patients in the study setting.
\end{abstract}

Methods: An institution based unmatched case-control study was conducted in Aksum town. Individuals who had a 6-month follow-up with complete individual information were included in the study. Document review and interviewer based techniques were used to collect the data. Binary logistic regression analysis was used to identify the determinant factors of non-adherence.

Results: A total of 411 (137 cases and 274 control) study participants were included in the study. The majority of them were male in sex. Having 2 years and above duration on ART [AOR $=7,95 \% \mathrm{Cl}(2.2,22.6)]$, history of adverse effect $[A O R=6.9,95 \% \mathrm{Cl}(1.4,32.9)]$, substance use $[A O R=5.3,95 \% \mathrm{Cl}(1.4,20.0)]$, living with parents $[A O R=3.4,95 \%$ $\mathrm{Cl}(1.2,10.3)]$, having depression symptom $[\mathrm{AOR}=3.3,95 \% \mathrm{Cl}(1.4,7.5)],<350 \mathrm{cell} / \mathrm{s} / \mathrm{mm}^{3}$ cluster of differentiation 4 count $[A O R=3.2,95 \% \mathrm{Cl}(1.8,5.8)]$ and low dietary diversity $[A O R=2,95 \% \mathrm{Cl}(1.1,3.7)]$ were found significant determinants of non-adherence to antiretroviral drug.

Conclusion: Program, social and individual related factors showed a statistically significant associated with nonadherence to antiretroviral therapy. Managing lifestyle by developing self-efficacy of individuals and treating related threat to improve adherence status of antiretroviral therapy is recommended in this study.

Keywords: Antiretroviral therapy, Case-control study, Non-adherence, Northern Ethiopia

\section{Background}

In 2013 globally, 35 million people living with Human Immunodeficiency Virus (HIV). Worthily, sub-Saharan Africa (23.5-26.1 million) people living with HIV which is $71 \%$ of the global prevalence UNAIDS [1]. Ethiopia, an estimated 793,700 $(716,300-893,200)$ people living with HIV/AIDS [2].

\footnotetext{
*Correspondence: yalassefa@gmail.com

${ }^{2}$ Department of Epidemiology and Biostatistics, Institute of Public Health, College of Medicine and Health Science, University of Gondar, 196 Gondar, Ethiopia

Full list of author information is available at the end of the article
}

Antiretroviral therapy (ART) is a proven treatment for HIV/ADS patients in improving the health status and quality of life of HIV/AIDS patients by reducing the rate of disease progression [3]. Appropriately taking of the treatment is the advisable option in order to obtain full benefits of ART; durable suppression of viral replication, reduced destruction of CD4 cells, prevention of viral resistance, promotion of immune reconstitution, and slowed disease progression [4]. Poor ART adherence is a notable public health problem in developing countries [5].

An individual considered as non-adherence for ART if he/she had a history of taking doses 2 or more hours 
before, and/or 2 or more hours after the time of a doctor's advice to take doses or missing doses completely (i.e., $<95 \%$ adherence $=$ missing $>2$ doses of 30 doses or $>3$ doses of 60 doses) $[5,6]$. In 2012, over 9.7 million people living with HIV in low- and middle-income countries were receiving ART, however, ensuring adherence to HIV treatment remains challenging in all countries [7].

Adherence of ART is a complex behavior, which is influenced by several determinants, majorly patient loss to follow-up and ensuring adherence to ART regimens remain major challenges in Ethiopia [2, 5].

Variables such as; availability of reminder, substance use, malnutrition, dietary diversity, CD4 count, depression symptom, adverse effect of ART and duration on ART were reported as a determinant factor for nonadherence to ART [5, 6, 8-12]. Duration on ART [13, $14]$ and CD4 count in $[11,15]$ were associated with nonadherence to ART. Determinant factors for non-adherence are multiple and have different effects. This study was aimed to identify determinants of non-adherence to ART among HIV-infected adults in Aksum town health facilities, northern Ethiopia.

\section{Methods}

An institution based unmatched case-control study was carried out from March 20 to May 15, 2015, in Aksum Health Center and Aksum Hospital, Aksum, Ethiopia. Aksum town is located $1067 \mathrm{~km}$ away in Northeast Ethiopia of Addis Ababa, the capital city of Ethiopia.

\section{Sample size and sampling procedure}

The sample size of the study was calculated by Epi-Info ${ }^{\mathrm{TM}} 7$ software Statcalc program using the following assumptions; proportion of non-adherence among not exposed (controls) $12.1 \%$, proportion of non-adherence among exposed (cases) $21.7 \%$, odds ratio 2.18 [16], 5\% level of significance, $80 \%$ power of the study and 1:2 case to control ratio.

All HIV/AIDS positive adults (18+ years old) who had at least three consecutive visits before a data collection period were considered as a study population of this study. The baseline data was collected from two health facilities using clinical record review. For the present study, study groups based on ART adherence status was defined as cases; patients who had a history of greater $5 \%$ (missing $>2$ doses out of 30 doses or $>3$ doses out of 60 doses) all of scheduled regimens which supposed to take in a month and controls were near-perfect (>95\%) take to dose of all regimens which supposed to take in a month $[17,18]$. All cases who had to follow-up during the data collection period were included in the study whereas controls were included by systematic random sampling techniques in every other four appointees.

\section{Data collection and data analysis}

The data were collected using chart review and interviewer administered techniques by two diploma nurses and three case managers working in ART clinics supervised by two bachelor nurse professionals. The structured questionnaire consisted of socio-demographic, socioeconomic, nutritional, medical and psychological were used for the data collection tool. A 1-day training on the objective of the study, confidentiality of information and interviewing techniques were given. Baseline information was filled out from ART registration and follow-up forms.

Dietary diversity was assessed by asking the number of reported different foods and food groups consumed in a household over a 24-h period of the data collection time, does not include food group consumed outside the home. It was categorized into three groups; low if $\leq 3$ food items consumed, medium if 4-6 food items consumed and high if $\geq 6$ food items consumed [19].

Patient Health Questionnaire (PHQ) with 9-items on which score ranges from 0 to 27 were used to assess the depression of the study participants. Individuals up on their response categorized into five categories as (no depression, mild depression, moderate depression, moderately severe depression and severe depression) [20].

Precoding and manual checking of the questionnaire were done by the principal investigator before the data entry. Data was entered using Epi-Info and exported to SPSS version 20 for further cleaning and analysis purpose. Binary logistic regression model used to identify the determinant factors. Collinearity diagnostic test was conducted using tolerance to check for co-linearity between independent variables and interaction effect. Variables in the bivariable analysis having a $\mathrm{p}$ value $<0.2$ were considered for multivariate analysis to adjust the confounders. The strength and presence of statistical association were assessed by OR, $p$ value and 95\% confidence interval $(95 \% \mathrm{CI})$. Variables with a $\mathrm{p}$ value $\leq 0.05$ were considered as statistically significant determinant factors of non-adherence to ART. Hosmer-Lemeshow goodness-of-fit test $(p=0.9289)$ was used to assess the fitness of the model.

\section{Results}

A total of 411 HIV-positive individuals (137 cases and 274 controls) who had at least 6 months ART followup participated in the study. More than half $(58.2 \%)$ of the study participants were male. The mean age $\pm(\mathrm{SD})$ at the time of data collection for cases and controls were $37.21( \pm 9.95)$ and $35( \pm 8.85)$ years, respectively (Table 1). 
Table 1 Socio-demographic characteristics at the time of presentation and during data collection time of cases and controls, Aksum town, northern Ethiopia 2015

\begin{tabular}{|c|c|c|}
\hline \multirow[t]{2}{*}{ Variables } & \multicolumn{2}{|c|}{ Frequency of adherence status } \\
\hline & Case, $\mathrm{n}(\%)$ & Control, n (\%) \\
\hline \multicolumn{3}{|l|}{ Sex } \\
\hline Male & $69(50.4)$ & $170(62)$ \\
\hline Female & $68(49.6)$ & $104(38)$ \\
\hline \multicolumn{3}{|l|}{ Age } \\
\hline $15-29$ & $23(16.8)$ & $54(19.7)$ \\
\hline $30-39$ & $60(43.8)$ & $127(46.4)$ \\
\hline $40-49$ & $35(25.5)$ & $74(27.0)$ \\
\hline$\geq 50$ & $19(13.9)$ & $19(6.9)$ \\
\hline \multicolumn{3}{|l|}{ Marital status } \\
\hline Single & $25(18.2)$ & $47(17.2)$ \\
\hline Married & $64(46.7)$ & $128(46.7)$ \\
\hline Widowed & $14(10.2)$ & $32(11.7)$ \\
\hline Divorced/separated & $34(24.8)$ & $67(24.4)$ \\
\hline \multicolumn{3}{|l|}{ Residence } \\
\hline Urban & $114(83.2)$ & $253(92.3)$ \\
\hline Rural & $23(16.8)$ & $21(7.7)$ \\
\hline \multicolumn{3}{|l|}{ Educational level (grade) } \\
\hline No formal education & $29(21.2)$ & $57(20.8)$ \\
\hline Primary education (1-8) & 68 (49.6) & $128(46.7)$ \\
\hline Secondary education (9-12) & $33(24.1)$ & $69(25.2)$ \\
\hline $12+$ & $7(5.1)$ & $20(7.3)$ \\
\hline \multicolumn{3}{|l|}{ Occupation } \\
\hline No occupation & $21(15.3)$ & $42(15.3)$ \\
\hline Government employed & $25(18.3)$ & $52(19)$ \\
\hline Business/self employed & $40(29.2)$ & $96(35)$ \\
\hline Daily laborer & $51(37.2)$ & $84(30.7)$ \\
\hline
\end{tabular}

Determinants of non-adherence to antiretroviral therapy

In multivariable analysis variables, such as duration of treatment, ART adverse effect, substance use, living condition, depression, CD4 cell count and dietary diversity were found to be independent determinant factors with non-adherence to ART.

Patients who had more than 2 years ART follow-up [AOR $=7,95 \% \mathrm{CI}(2.2,22.6)]$ were 7 times more likely to not adhere as compared to those who had 6-12 months follow-up. Patients who had a history of ART adverse drug effect $[\mathrm{AOR}=6.9,95 \% \mathrm{CI}(1.4,32.9)]$ were 6.9 times more likely to be non-adherent as compare to the counterpart. HIV-positive substance user [AOR $=5.3,95 \% \mathrm{CI}$ $(1.4,20)]$ individuals who were 5.3 times more likely to be non-adherence as compared with the counterpart.

Non-adherence were 3.4 times more likely to occur among those who live with their parents $[\mathrm{AOR}=3.4$, $95 \%$ CI $(1.2,10.3)]$ as compared to those who live alone. This study also showed that depression is associated with non-adherence of ART. The odds of non-adherence were 3.3 times more likely to those who had depression symptom $[\mathrm{AOR}=3.3,95 \% \mathrm{CI}(1.4,7.5)]$ as compared to their counterparts.

HIV-positive individuals who had $<350$ cells $/ \mathrm{mm}^{3} \mathrm{CD} 4$ cell count $[\mathrm{AOR}=3.2,95 \% \mathrm{CI}(1.8,5.8)]$ were 3.2 times more likely to not adhere as compared to those HIVpositive individuals who had CD4 cell count $\geq 350$ cells/ $\mathrm{mm}^{3}$. Moreover, low dietary diversity $[\mathrm{AOR}=2,95 \% \mathrm{CI}$ (1.1-3.7)] were two times to not adhere as compared to the counterparts (Table 2).

\section{Discussion}

ART has a proven clinical benefit in HIV-infected people by slow downing the progressing to AIDS. Incomplete adherence to the treatment leads to immune suppression and the selection drug resistant HIV [21]. Non-adherence increases HIV-related morbidity and mortality [22]. Numerous studies were conducted on the determinants of ART drug-adherence and/or non-adherence of HIV/ AIDS patients in the country. However, studies signify the consequence of non-adherence is one or more factors that may have different effects consequently; the study setting, socio-demographic characteristics of the study participants, and sample size. This study showed that having 2 years and above duration on ART, depression symptoms, history of ART adverse effect, substance use, living with parents, $<350$ cells $/ \mathrm{mm}^{3} \mathrm{CD} 4$ count and low dietary diversity in the household as determinant factors for non-adherence to ART.

Coherent with the previous studies in Ethiopia [13, 23] HIV-positive participants who had more than 2 years ART follow-up were not taken ART drugs appropriately. This finding was also coherent with the Asia study conducted in Vientiane, Lao PDR [24]. Findings of Asia [25, 26] inconsistent with the present study, patients who have been on ART for short period were more likely to be non-adherent. The possible reason for the discrepancy could be these studies were included those patients who had less than 6 months' duration on ART since ART at an early phase of treatment may have severed adverse drug effects. On top of the treatment duration of the patients, the accessibility of health facilities, living conditions, socio-demographic characteristics of the population in Asia is differ from Ethiopia which might have effect on the adherence status of the patient.

Like the report of previous studies conducted in Ethiopia [11] and in Nepal [26] in the present study, participants that had experience of adverse drug effect during their medication were more likely to non-adherence to ART. But, this study is not consistent with a systematic review of Asian developing countries in 2012 reported [27]. The possible explanation will be they already 
Table 2 Binary and multiple logistic regression model showing determinants of non-adherence to antiretroviral therapy, among adults on ART Aksum town, northern Ethiopia 2015

\begin{tabular}{|c|c|c|c|c|}
\hline \multirow[t]{2}{*}{ Explanatory variables } & \multicolumn{2}{|l|}{ Adherence status to ART } & \multirow[t]{2}{*}{ COR $(95 \% \mathrm{Cl})$} & \multirow[t]{2}{*}{ AOR $(95 \% \mathrm{Cl})$} \\
\hline & Non-adherent number (\%) & Adherent number (\%) & & \\
\hline \multicolumn{5}{|l|}{ Sex } \\
\hline Male & $69(50.4)$ & $170(62)$ & 1 & 1 \\
\hline Female & $68(49.6)$ & $104(38)$ & $1.6(1.1-2.4)$ & $1.4(0.8-2.4)$ \\
\hline \multicolumn{5}{|l|}{ Age } \\
\hline $18-29$ & $23(16.8)$ & $54(19.7)$ & 1 & 1 \\
\hline $30-39$ & $60(43.8)$ & $127(46.4)$ & $1.1(0.6-2.0)$ & $1.1(0.5-2.4)$ \\
\hline $40-49$ & $35(25.5)$ & $74(27)$ & $1.1(0.6-2.1)$ & $0.7(0.3-1.7)$ \\
\hline$\geq 50$ & $19(13.9)$ & $19(6.9)$ & $2.3(1.1-5.2)$ & $1.7(0.6-5.0)$ \\
\hline \multicolumn{5}{|l|}{ Residence } \\
\hline Urban & $114(83.2)$ & $253(92.3)$ & 1 & 1 \\
\hline Rural & $23(16.8)$ & $21(76.7)$ & $2.4(1.3-4.6)$ & $1.4(0.5-4.0$ \\
\hline \multicolumn{5}{|l|}{ Occupation } \\
\hline No occupation & $21(15.3)$ & $42(15.3)$ & 1 & 1 \\
\hline Employed & $25(18.3)$ & $52(19)$ & $0.9(0.5-2)$ & $1.4(0.5-4.2)$ \\
\hline Business & $40(29.2)$ & $96(35)$ & $0.8(0.4-1.6)$ & $1.8(0.7-4.0)$ \\
\hline Farmer & $14(10.2)$ & $10(3.7)$ & $2.8(1.1-7.4)$ & $2.3(0.5-10.3)$ \\
\hline Daily laborer & $37(27)$ & $74(27)$ & $1(0.5-1.9)$ & $1.9(0.8-4.7)$ \\
\hline \multicolumn{5}{|l|}{ Duration on ART (months) } \\
\hline $6-12$ & $7(5.1)$ & $38(13.9)$ & 1 & 1 \\
\hline $13-24$ & $14(10.2)$ & $38(13.9)$ & $2.0(0.7-5.5)$ & $2(0.5-8.8)$ \\
\hline$\geq 25$ & $116(84.7)$ & $198(72.2)$ & $3.2(1.47 .4)$ & $7(2.2,22.6)^{* *}$ \\
\hline \multicolumn{5}{|l|}{ ART adverse effect } \\
\hline Yes & $26(19)$ & $3(1.1)$ & $21.2(6.3-71.3)$ & $6.9(1.4,32.9)^{* *}$ \\
\hline No & $111(81)$ & $271(98.9)$ & 1 & 1 \\
\hline \multicolumn{5}{|l|}{ Substance use } \\
\hline Yes & $21(15.3)$ & $5(1.8)$ & $9.7(3.6-26.5)$ & $5.3(1.4-20.0)^{*}$ \\
\hline No & $116(84.7)$ & $269(98.2)$ & 1 & 1 \\
\hline \multicolumn{5}{|l|}{ Live with } \\
\hline Alone & $33(24.1)$ & $83(30.3)$ & 1 & 1 \\
\hline Parents & $18(13.1)$ & $21(7.7)$ & $2.2(1.02-4.6)$ & $3.4(1.2-10.3)^{*}$ \\
\hline Family & $86(62.8)$ & $170(62)$ & $1.3(0.8-2.1)$ & $1.5(0.8-2.8)$ \\
\hline \multicolumn{5}{|l|}{ Depression status } \\
\hline Depressed & $41(29.9)$ & $19(6.9)$ & $5.7(3.2-10.4)$ & $3.3(1.4-7.5)^{*}$ \\
\hline Not depressed & $96(70.1)$ & $255(93.1)$ & 1 & 1 \\
\hline \multicolumn{5}{|c|}{ CD4 cell count (cells $/ \mathrm{mm}^{3}$ ) } \\
\hline$<350$ & $58(42.3)$ & $45(16.4)$ & $3.7(2.4-6.0)$ & $3.2(1.8-5.8)^{*}$ \\
\hline$\geq 350$ & $79(57.7)$ & $229(83.6)$ & 1 & 1 \\
\hline \multicolumn{5}{|l|}{ Dietary diversity } \\
\hline Low & $57(41.6)$ & $43(15.7)$ & $3.8(2.4-6.1)$ & $2(1.1-3.7)^{*}$ \\
\hline Medium and above & $80(58.4)$ & $231(84.3)$ & 1 & 1 \\
\hline \multicolumn{5}{|l|}{ Daily eating pattern } \\
\hline$\leq 2$ meals & $69(50.4)$ & $103(37.6)$ & $1.7(1.1-2.6)$ & $1.01(0.6-1.8)$ \\
\hline$\geq 3$ meals & $68(49.6)$ & $171(62.4)$ & 1 & 1 \\
\hline \multicolumn{5}{|l|}{ Opportunistic infection } \\
\hline Yes & $28(20.4)$ & $5(1.8)$ & $13.8(5.2-36.7)$ & $3.6(1-13.1)$ \\
\hline No & $109(79.6)$ & $269(98.2)$ & 1 & 1 \\
\hline
\end{tabular}


Table 2 continued

\begin{tabular}{|c|c|c|c|c|}
\hline \multirow[t]{2}{*}{ Explanatory variables } & \multicolumn{2}{|l|}{ Adherence status to ART } & \multirow[t]{2}{*}{ COR $(95 \% \mathrm{Cl})$} & \multirow[t]{2}{*}{ AOR $(95 \% \mathrm{CI})$} \\
\hline & Non-adherent number (\%) & Adherent number (\%) & & \\
\hline \multicolumn{5}{|l|}{ Reminder use } \\
\hline Yes & $127(92.7)$ & $268(97.8)$ & $0.3(0.1-0.8)$ & $0.5(0 .-2.0)$ \\
\hline No & $10(7.3)$ & $6(2.2)$ & 1 & 1 \\
\hline \multicolumn{5}{|l|}{ Stigma } \\
\hline Yes & $17(12.4)$ & $10(3.6)$ & $3.7(1.7-8.4)$ & $2.8(0.9-8.5)$ \\
\hline No & $120(87.6)$ & $264(96.4)$ & 1 & 1 \\
\hline \multicolumn{5}{|l|}{ WHO stage } \\
\hline Stage I & $16(11.7)$ & $68(24.8)$ & 1 & 1 \\
\hline Stage II and above & $121(88.3)$ & $206(75.2)$ & $2.5(1.4-4.5)$ & $1.6(0.8-3.5)$ \\
\hline \multicolumn{5}{|l|}{ BMI } \\
\hline Under weight & $38(27.7)$ & $41(15)$ & 1 & 1 \\
\hline Normal & $97(70.8)$ & $224(81.7)$ & $0.5(0.3-0.8)$ & $0.7(0.3-1.3)$ \\
\hline Over weight & $2(1.5)$ & $9(3.3)$ & $0.2(0.1-1.2)$ & $0.4(0.01-3.0)$ \\
\hline \multicolumn{5}{|l|}{ Treatment other than ART } \\
\hline Yes & $41(29.9)$ & $40(14.6)$ & $2.5(1.5-4.1)$ & $1.4(0.7-3.0)$ \\
\hline No & $96(70.1)$ & $234(85.4)$ & 1 & 1 \\
\hline
\end{tabular}

${ }^{*} p<0.05$

*** $\mathrm{p}<0.001$

counselled on the possible side effects of the drug during their medication follow-up time.

Substance uses among patients during ART medication was also found to be the independent determinant factors of non-adherence, a finding consistent with a study done in southern Ethiopia [16], Tanzania [28] and Nepal [26].

In the present study, the living conditions are a determinant factor of non-adherence. Patients living with their families were more likely to non-adherence of ART drug as compared to those living independent from their families, consistent with previous study done in southern Ethiopia [29] inconsistent with a study done in Canada [30] and Cambodia [31]. The difference may be due to clients' self-efficacy and attitude towards ART medication is stumpy in the study setting, even at a country level.

The presence of depressive symptoms during medication is also reported as one of determinant factor for ART drug adherence, supported with studies done in South-west Ethiopia [14, 29], South Africa [32] and Netherlands [33]. Possibly depressed patients could easily forget to take their dose while they managed the depression symptoms.

Similar to other studies conducted in Ethiopia [15, 34, $35]$, and in Africa [32, 36] the level of CD4 count during initiation of treatment have independent effect for adherence status. Non-adherence was higher among patients with a CD4 count $<350$ cells $/ \mathrm{mm}^{3}$ compared to their counterparts. The finding is supported by studies in Ethiopia [15, 34, 35] however, a finding reported in Yirgalem Hospital, southern Ethiopia [23] was not consistent with the present study. This may be due to the previous study controlling for both WHO stages and CD4 cell count for the initiation criteria of ART.

Moreover, low dietary habits of the patient are reported as the independent determinant factors of non-adherence. This finding is supported by reports in South and North Ethiopia [15, 16] and Zambia [37].

Unlike previous studies, socio-demographic factors such as sex, age, residence, occupation, eating pattern and patient level factors; didn't show statistically significant association with non-adherence of ART. This may be because of in this locales the barriers of non-adherence were beyond the listed variables.

Since identifications of case and controls were done based on the registration log book and individual chart review, this paper may be prone to misclassification bias. Because of the adherence status of the patient were assessed by patient self-report, the non-adherence status may underestimate. Moreover, information bias was also a problem while assessing dietary diversity, substance use and depression symptom.

\section{Conclusion}

Having more than 2-year duration on ART follow-up, experiencing, adverse ART drug effect, substance use, living with parents, having depression symptom, CD4 cell count $<350$ cells $/ \mathrm{mm}^{3}$ and low dietary diversity 
were all found independent determinant factors of nonadherence of ART drug. Defining the adherence status with viral load suppression and/or measured by detectable viral load during chronic care and identifying the treatment outcome of non-adherence patient is recommended for future researcher.

\section{Authors' contributions}

BBG, YK, YAG, MKY, DT and MA equally participated in this study. All authors read and approved the final manuscript.

\section{Author details}

${ }^{1}$ Department of Public Health, Health Science College, Axum University, Axum, Ethiopia. ${ }^{2}$ Department of Epidemiology and Biostatistics, Institute of Public Health, College of Medicine and Health Science, University of Gondar, 196 Gondar, Ethiopia.

\section{Acknowledgements}

Aksum Hospital and Health Center staff, study participants, data collectors and supervisors deserve acknowledgement for their unreserved support.

\section{Competing interests}

BBG, YK, and YAG participated from objective formulation to manuscript drafting. MK, DT and MA are participated during data analysis and manuscript drafting. All authors shared professional contribution for this study.

\section{Availability of data and materials}

All data underlying the findings are fully available online without restriction. Data are available in figure share: https://figshare.com/s/ ca4e9a1ae825395ba236.

\section{Ethics approval and consent to participate}

The study was conducted after receiving ethical approval from Intuitional Review Committee of the University of Gondar, college of Medicine and Health Science, Institute of Public Health. Before the ethical approval, the proposal was provided to academic reviewers to assure the ethical issues. Finally, the ethical review committee approved the oral consent. Permission letter was obtained from the respective health institutions (Aksum Town Health Office, Aksum Health Center and Aksum Hospital) persons in charge and from ART Clinic nurses and data managers. Study participants were informed of the purpose of the study and obtained written informed consent. To ensure confidentiality, names were not mentioned in the data collection tools and result reports.

Received: 25 October 2016 Accepted: 11 March 2017

Published online: 21 March 2017

\section{References}

1. UNAIDS. The Gap Report Switzerland Geneva updated Sept 2014. July 2014.

2. HIV AIDS Prevention and Control Organization. Federal Democratic Republic of Ethiopia country progress report on the HIV response. Addis Ababa:MOH; 2014.

3. Joint United Nations Programme on HIV/AIDS. United Nation AIDS world AIDS day report 2011 (Faster, Smarter, Better). Geneva:UNAIDS; 2011.

4. Steel G, Nwokike J, Joshi MP. Development of a multi-method tool to measure ART adherence in resource-constrained settings: the South Africa experience. RPM Plus. Arlington, VA: Management Sciences for Health; 2007

5. Asmare M, Aychiluhem M, Ayana M, Jara D. Level of ART adherence and associated factors among HIV sero-positive adult on highly active antiretroviral therapy in Debre Markos Referral Hospital, Northwest Ethiopia. J Antivir Antiretrovir. 2014;6:120-6. doi:10.4172/jaa.10000107.

6. Sarna A, Kellerman S. Access to antiretroviral therapy for adults and children with HIV infection in developing countries: horizons studies, 2002-2008. Public Health Rep. 2010;125(2):305-15.
7. The World Health Organization. Global update on HIV treatment: results, impact and opportunities. 2013.

8. Mills EJ, et al. Adherence to antiretroviral therapy in sub-Saharan Africa and North America: a meta-analysis. JAMA. 2006;296(6):679-90.

9. Stein MD, et al. Adherence to antiretroviral therapy among HIV-infected methadone patients: effect of ongoing illicit drug use. Am J Drug Alcohol Abuse. 2000;26(2):195-205.

10. Ortego $C$, et al. Adherence to highly active antiretroviral therapy (HAART) a meta-analysis. AIDS Behav. 2011;15(7):1381-96.

11. Tessema B, et al. Magnitude and determinants of non-adherence and nonreadiness to highly active antiretroviral therapy among people living with HIV/AIDS in Northwest Ethiopia: a cross-sectional study. AIDS Res Ther. 2010;7(1):1.

12. Ethiopian Federal Minstry of Health. National Guidelines for Comprehensive HIV Prevention, Care and Treatment. Addis Ababa: Ethiopian Federal Minstry of Health; 2014.

13. Mitiku H, Abdosh T, Teklemariam Z. Factors affecting adherence to antiretroviral treatment in Harari National Regional State, eastern Ethiopia. ISRN AIDS. 2013; doi:10.1155/2013/960954.

14. Amberbir A, et al. Predictors of adherence to antiretroviral therapy among HIV-infected persons: a prospective study in Southwest Ethiopia. BMC Public Health. 2008;8(1):1.

15. Berhe N, Tegabu D, Alemayehu M. Effect of nutritional factors on adherence to antiretroviral therapy among HIV-infected adults: a case control study in northern Ethiopia. BMC Infect Dis. 2013;13(1):1

16. Bitew BD, et al. Determinants of none-adherence to antiretroviral therapy among HIV-infected adults in Arba Minch General Hospital, Gamo Gofa Zone, southern Ethiopia: a case control study. Am J Health Res. 2014;5(2):234-40.

17. Kaplan JE, Benson C, Holmes KK, Brooks JT, Pau A, Masur H, Centers for Disease Control and Prevention (CDC), National Institutes of Health, HIV Medicine Association of the Infectious Diseases Society of America. Guidelines for prevention and treatment of opportunistic infections in HIV-infected adults and adolescents. MMWR Recomm Rep. 2009;58(RR-4):1-207.

18. Machtinger EL, Bangsberg DR. Adherence to HIV antiretroviral therapy HIV InSite Knowledge Base chapter. 2006.

19. De Matteis A, et al. Baseline survey of food security and nutrition in Mozambique. Maputo: Technical Secretariat for Food Security and Nutrition: Vulnerability Analysis Group; 2006.

20. Kroenke K, Spitzer RL. The PHQ-9: a new depression diagnostic and severity measure. Psychiatr Ann. 2002;32(9):1-7

21. Bangsberg DR, Moss AR, Deeks SG. Paradoxes of adherence and drug resistance to HIV antiretroviral therapy. J Antimicrob Chemother. 2004;53(5):696-9.

22. Haddad PM, Brain C, Scott J. Nonadherence with antipsychotic medication in schizophrenia: challenges and management strategies. Patient Relat Outcome Meas. 2014;5:43-62.

23. Irano ZA, et al. Determinants of non-adherence to antiretroviral therapy and modeling progression of adherence level: at Yirgalem Regional Hospital, Ethiopia; January, 2012. Int J Med Health Sci Res. 2015;2(1):1-14.

24. Hansana $\mathrm{V}$, et al. Adherence to antiretroviral therapy (ART) among people living with HIV (PLHIV): a cross-sectional survey to measure in Lao PDR. BMC Public Health. 2013;13:617.

25. Jiamsakul A, Kumarasamy N, Ditangco R, Li PC, Phanuphak P, Sirisanthana T, Sungkanuparph S, Kantipong P, Lee CK, Mustafa M, Merati T. Factors associated with suboptimal adherence to antiretroviral therapy in Asia. J Int AIDS Soc. 2014:17(1):18911. doi:10.7448/IAS.17.1.18911.

26. Wasti SP, et al. Factors influencing adherence to antiretroviral treatment in Nepal: a mixed-methods study. PLoS ONE. 2012;7(5):e35547.

27. Wasti SP, et al. Factors influencing adherence to antiretroviral treatment in Asian developing countries: a systematic review. Tropl Med Int Health. 2012:17(1):71-81.

28. Idindili B, Jullu B, Mugusi F, Tanner M. A case-control study of factors associated with non-adherent to antiretroviral therapy among HIV infected people in Pwani Region, eastern Tanzania. Tanzania J Health Res. 2012:14(3):194-203.

29. Alagaw A, et al. Factors associated with antiretroviral treatment adherence among adult patients in Wolaita Soddo Hospital, Wolaita Zone, southern Ethiopia. Sci J Public Health. 2014;2:69-77.

30. Godin $\mathrm{G}$, et al. Prediction of adherence to antiretroviral therapy: a oneyear longitudinal study. AIDS care. 2005;17(4):493-504. 
31. Spire B, et al. Adherence to antiretroviral therapy in patients enrolled in a comprehensive care program in Cambodia: a 24-month follow-up assessment. Antivir Ther. 2008;13(5):697-703.

32. Peltzer $\mathrm{K}$, et al. Antiretroviral treatment adherence among HIV patients in KwaZulu-Natal, South Africa. BMC Public Health. 2010;10(1):1.

33. Langebeek $\mathrm{N}$, et al. Predictors and correlates of adherence to combination antiretroviral therapy (ART) for chronic HIV infection: a meta-analysis. BMC Med. 2014;12(1):142.

34. Biressaw S, et al. Adherence to antiretroviral therapy and associated factors among HIV infected children in Ethiopia: unannounced home-based pill count versus caregivers' report. BMC Pediatr. 2013;13(1):132.
35. Amberbir A, et al. Predictors of adherence to antiretroviral therapy among HIV-infected persons: a prospective study in Southwest Ethiopia. BMC Public Health. 2008;8(1):265.

36. Mbuagbaw $L$, et al. Trends and determining factors associated with adherence to antiretroviral therapy (ART) in Cameroon: a systematic review and analysis of the CAMPS trial. AIDS Res Ther. 2012;9(1):1.

37. Sasaki Y, et al. Adherence to antiretroviral therapy (ART) during the early months of treatment in rural Zambia: influence of demographic characteristics and social surroundings of patients. Ann Clin Microbio Antimicrob. 2012;11(1):1.

\section{Submit your next manuscript to BioMed Central and we will help you at every step:}

- We accept pre-submission inquiries

- Our selector tool helps you to find the most relevant journal

- We provide round the clock customer support

- Convenient online submission

- Thorough peer review

- Inclusion in PubMed and all major indexing services

- Maximum visibility for your research

Submit your manuscript at www.biomedcentral.com/submit 